\title{
Diamond-Like-Carbon Coating Over Prosthetic Screws: Analysis Of The Torque Maintenance After Retorque
}

Research Article

Rafaela Cristiane Canavezi1 ${ }^{1}$, Viviane Maria Gonçalves de Figueiredo ${ }^{2}$, Alecsandro Moura de Silva ${ }^{3}$, Laura Souto Soares Lepesqueur ${ }^{4}$, José Renato Cavalcanti Queiroz ${ }^{5}$, Marcos Massi ${ }^{6}$, Renata Falchete do Prado ${ }^{7 *}$, Lafayette Nogueira Junior ${ }^{8}$

${ }^{1}$ Department of Dental Materials and Prosthodontics, Institute of Science and Technology of São José dos Campos, São Paulo State University (UNESP), Sao Jose dos Campos, 12245000 Brazil.

${ }^{2}$ Department of Dental Materials and Prosthodontics, Institute of Science and Technology of São José dos Campos, São Paulo State University (UNESP), Sao Jose dos Campos12245000, Brazil.

${ }^{3}$ Department of Dentistry, UNITAU - University of Taubaté, Taubaté, SP, Brazil.

${ }^{4}$ Department of Dental Materials and Prosthodontics, Institute of Science and Technology of São José dos Campos, São Paulo State University (UNESP), Sao Jose dos Campos 12245000, Brazil.

${ }^{5}$ Department of Biotechnology, UnP - Laureate University, Natal, 59010020 Brazil.

${ }^{6}$ Mackenzie Presbyterian University, School of Engineering-PPGEMN, São Paulo 01302907 Brazil.

${ }^{7}$ Department of Dental Materials and Prosthodontics, Institute of Science and Technology of São José dos Campos, São Paulo State University (UNESP), Sao Jose dos Campos, 12245000 Brazil.

${ }^{8}$ Department of Dental Materials and Prosthodontics, Institute of Science and Technology of São José dos Campos, São Paulo State University (UNESP), Sao Jose dos Campos, 12245000 Brazil.

\section{Abstract}

Background: The retorqueing of fixing screws has become a routine in clinical practice, aiming to reduce the risk of screw loosening; however, there are not in vitro studies that evaluate the effect of this clinical practice in nanofilm-coated screws. The objective of this study was to verify the torque maintenance of prosthetic pillar screws coated with diamond-doped diamond-like nanofilm (DD-DLC), submitted to retorque, after mechanical fatigue, in external (EH) and internal hexagonal connections $(\mathrm{IH})$.

Materials and Methods: Different implants and treatments of the prosthetic screws resulted in eight experimental groups $(\mathrm{n}=5)$ : untreated and not submitted to fatigue (EH-CON) (IH-CON); untreated and fatigued control (EH-F) (IH-F); with DLC nanofilm and fatigued (EH-DLCF) (IH-DLCF) and with DD-DLC nanofilm and fatigued (EH-DD-DLCF) (IH-DDDCLF). The coatings were plasma-deposited through the Plasma Enhanced Chemical Vapor Deposition method. The samples were exposed to one million fatigue cycles; samples were submitted to reverse torque; samples were retorqued; then samples were re-submitted to another one million mechanical cycles. After fatigue, the reverse torque of the screws was performed to determine the torque maintenance. The screws were qualitatively analyzed through a scanning electron microscope. The statistical analysis used ANOVA.

Results: There was no interaction between the studied factors. The treatment of screws and connection type did not present significant differences. The coatings did not interfere in the adaptation of the screw to the implant.

Conclusion: The prosthetic screws with DLC and DD-DLC nanofilms, after retorque, did not present increased torque maintenance.

Keywords: Dental Implant; Screw Loosening; Reverse Torque; Retorque; Diamond-Like Carbon Coating.

\section{*Corresponding Author:}

Renata Falchete do Prado,

Department of Dental Materials and Prosthodontics, Institute of Science and Technology of São José dos Campos, São Paulo State University (UNESP), Sao Jose dos Campos, 12245000 Brazil.

Tel: +551239479036

Fax: +551239479010

E-mail: renatafalchete@hotmail.com

Received: Ocotber 20, 2021

Accepted: November 13, 2021

Published: November 29, 2021

Citation: Rafaela Cristiane Canavezi, Viviane Maria Gonçalves de Figueiredo, Alecsandro Moura de Silva, Laura Souto Soares Lepesqueur, José Renato Cavalcanti Queiroz, Marcos Massi, Renata Falchete do Prado, Lafayette Nogueira Junior. Diamond-Like-Carbon Coating Over Prosthetic Screws: Analysis Of The Torque Maintenance After Retorque. Int J Dentistry Oral Sci. 2021;8(11):5157-5163. doi: http://dx.doi.org/10.19070/2377-8075-210001036

Copyright: Renata Falchete do Prado 2021 . This is an open-access article distributed under the terms of the Creative Commons Attribution License, which permits unrestricted use, distribution and reproduction in any medium, provided the original author and source are credited. 


\section{Introduction}

The complications of prostheses over implants present biological and mechanical levels. Among the mechanical complications, the loosening and fracture of the prosthetic screw, abutment fracture, retention loss, crown cementation loss, and implant fracture may be listed [1]. The screw loosening is the most common mechanical cause associated with the failure of prostheses over implants [2]. The adaptation between the abutment and the implant, the parafunction, and/or oblique loads interfere in the screwed junction resistance [3], and the corrosion also may interfere in this issue [4].

In an attempt to minimize or control loosening, new implant, and pillars designs, and screws surface treatments have been proposed [5]. The prosthetic screw surface and material composition promote changes in the coefficient of friction, to which the preload value is inversely proportional [6].

The coating of the screw threads, as proposed in some studies, is based on the principle of change in the coefficient of friction of this surface (dry lubrication) [7], which improves its tribological properties, generating more longitudinal stability in the pillar-implant system with less screw loosening incidence [8]. Such coating has been especially applied as carbon-like diamond (DLC) films, grown from plasma [9].

An investigation using DCL-coated screws in hexagonal connections, after fatigue simulation, demonstrated that samples with the DLC coating were more resistant to an applied force than those without the coating [7] and presented better torque maintenance values than the ones with other coatings [10]. The DLC coating of titanium screws in internal and external hexagonal connections, after mechanical fatigue, had not shown damage to screws threads [6].

Another class of carbon-based nanofilms is based on nanocrystalline diamond [11]. A mixture of nanodiamond nanoparticles with different forms of sp2-bonded carbon has been used for improved tribological properties of industrial oils and greases. These nanodiamond nanoparticles may be used as additives to lubricants. They are one of the most promising nanocolloidal additives [12].

Previous studies have shown that the retorquing, $10 \mathrm{~min}$. after first torque, caused an insignificant maladjustment effect of titanium screws, suggesting that this procedure could be used routinely [13]. The retorque evaluation of titanium and gold screws in six months to one year of fatigue process proved that the titanium screws stability was greater than the gold screws and after one year, titanium screws were less stable due to torque loss when maladjustments were found [14]. After mechanical cycling, retorque did not present a significant difference between adapted and non-adapted prostheses; hence, the retorque of gold and titanium screws is indicated for multiple prostheses, since there was a reduction in the loosening of such screws [15].

The purpose of this study was to evaluate the torque maintenance of prosthetic pillar screws coated with diamond-dopped DLC nanofilm after mechanical fatigue, submitted to retorque in external $(\mathrm{EH})$ and internal hexagonal connections (IH).

The considered null hypotheses were the following: H01 - The torque maintenance of nanofilm-treated screws will not present superior values than the ones of uncoated/non-fatigued screws; H02 - internal hexagonal connections will not present torque maintenance values higher than the ones found on external hexagonal connections, and $\mathrm{H} 03$ - diamond-dopped DLC nanofilm will not present difference in torque maintenance values when compared to DLC nanofilm.

\section{Materials And Methods}

\section{Material}

The materials used in this research are listed in Table 1.

\section{Experimental and Sample Groups}

This study was performed with the following experimental groups:

EH-CON: Prosthetic pillar screws, EH connection, non-fatigued,

Table 1. Commercial name, material, manufacturer and composition of materials used in this study.

\begin{tabular}{|c|c|c|c|}
\hline Commercial Name & Material & Manufacturer & Composition \\
\hline ConectAr Implants & $\begin{array}{l}\text { Internal hexagon implants } \\
4.0 \times 13 \mathrm{~mm}\end{array}$ & $\begin{array}{c}\text { Conexão Sistemas de Pró- } \\
\text { tese, São Paulo, Brazil }\end{array}$ & $\begin{array}{l}\text { Commercially pure titanium, grade } 4 \text {, } \\
\text { ASTM F67 }\end{array}$ \\
\hline $\begin{array}{l}\text { Master Grip Im- } \\
\text { plants }\end{array}$ & $\begin{array}{l}\text { External hexagon implants } \\
4.0 \times 13 \mathrm{~mm}\end{array}$ & $\begin{array}{c}\text { Conexão Sistemas de Pró- } \\
\text { tese, São Paulo, Brazil }\end{array}$ & $\begin{array}{l}\text { Commercially pure titanium, grade } 4 \text {, } \\
\text { ASTM F67 }\end{array}$ \\
\hline $\begin{array}{l}\text { Preparation pillars } \\
\text { (bearing sleeve) }\end{array}$ & $\begin{array}{c}\text { Preparable titanium pillar for } \\
\text { internal hexagon implants of } 3.75 \\
\text { mm diameter }\end{array}$ & $\begin{array}{l}\text { Conexão Sistemas de Pró- } \\
\text { tese, São Paulo, Brazil }\end{array}$ & $\begin{array}{l}\text { Commercially pure titanium, grade } 2 \text {, } \\
\text { ASTM F67 }\end{array}$ \\
\hline $\begin{array}{l}\text { Preparation pillars } \\
\text { (bearing sleeve) }\end{array}$ & $\begin{array}{c}\text { Preparable titanium pillar for } \\
\text { external hexagon implants of } 3.75 \\
\text { mm diameter }\end{array}$ & $\begin{array}{l}\text { Conexão Sistemas de Pró- } \\
\text { tese, São Paulo, Brazil }\end{array}$ & $\begin{array}{l}\text { Commercially pure titanium, grade } 2 \text {, } \\
\text { ASTM F67 }\end{array}$ \\
\hline $\begin{array}{l}\text { Conect Air prosthet- } \\
\text { ic pillar screws }\end{array}$ & $\begin{array}{l}\text { Titanium screws for internal hexa- } \\
\text { gon implants of } 3.75 \mathrm{~mm} \text { diameter }\end{array}$ & $\begin{array}{c}\text { Conexão Sistemas de Pró- } \\
\text { tese, São Paulo, Brazil }\end{array}$ & Titanium alloy, ASTM F-136 \\
\hline $\begin{array}{l}\text { Master Grip pros- } \\
\text { thetic pillar screws }\end{array}$ & $\begin{array}{l}\text { Titanium screws for external hexa- } \\
\text { gon implants of } 3.75 \mathrm{~mm} \text { diameter }\end{array}$ & $\begin{array}{c}\text { Conexão Sistemas de Pró- } \\
\text { tese, São Paulo, Brazil }\end{array}$ & Titanium alloy, ASTM F-136 \\
\hline Temp Bond NE & Zinc oxide-based cement & $\begin{array}{c}\text { Kavo - Kerr ,Potsdam, } \\
\text { Germany }\end{array}$ & $\begin{array}{l}\text { Base: } 44 \mathrm{~g} \text { of zinc oxide, mineral oil, } \\
\text { lecithin, starch, iron oxide pigments } \\
\text { Catalyzing putty: } 14 \mathrm{~g} \text { poly organic acids }\end{array}$ \\
\hline
\end{tabular}


untreated.

EH-CONF: Prosthetic pillar screws, EH connection, fatigued, untreated.

EH-DLCF: Prosthetic pillar screws, EH connection, fatigued, pre-treated with DLC nanofilm.

EH-DD-DLCF: Prosthetic pillar screws, EH connection, fatigued, pre-treated with diamond-doped DLC nanofilm (DDDLC).

IH-CON: Prosthetic pillar screws, IH connection, non-fatigued, untreated.

IH-CONF: Prosthetic pillar screws, IH connection, fatigued, untreated.

IH-DLCF: Prosthetic pillar screws, IH connection, fatigued, pretreated with DLC nanofilm.

IH-DD-DLCF: Prosthetic pillar screws, IH connection, fatigued, pre-treated with DD-DLC nanofilm.

For the IH-CON and EH-CON groups, new, non-fatigued screws were used. Each experimental group had five specimens. The sampling calculation was performed based on the standard deviation of a similar study [6], using a data analysis statistics software (Minitab version 1.6, for Windows, Pennsylvania, USA), with $80 \%$ of sampling power.

\section{Preparation of specimens}

The implants were installed in polyurethane resin blocks $(22 \mathrm{x}$ $15 \mathrm{~mm}$ - Polyurethane F16 with mineral load (RZ 30150-Axson, France - elastic modulus of 3.6 GPa.). Implants were milled at an inclination of $90^{\circ}$ and installed with the assistance of a manual ratchet, while blocks were fixed. The applied torque for the installation of implants was $45 \mathrm{~N} .3 \mathrm{~mm}$ of the implant threads were left exposed (ISO 14801), whereas the pillar had a standard height of $8 \mathrm{~mm}$.

The screws were coated through the Plasma-Enhanced Chemical Vapor Deposition technique (PECVD). For the DLC and diamond-doped DCL nanofilms, the gas was the hexane (C6H14) and the hexane with diamond nanoparticles $(2 \mathrm{~g} / \mathrm{L})$, respectively. In this deposition process, the screws were positioned at a sample holder, which assured proper positioning. The deposition was performed as previously described [6].

After deposition, screws were torqued with a digital torque meter (TQ-680, Instrutherm Measuring Instruments São Paulo Brazil). The torque of $20 \mathrm{Ncm}$ was performed in IH and the torque of $30 \mathrm{Ncm}$ was performed in $\mathrm{EH}$, according to manufacturer recommendation. Ten minutes after the application of the initial torque, the procedure was repeated.

\section{Experimental crown}

Nickel-chrome alloy total crowns (Litecast B Will-Ceram/USA) were prepared in a conical-trunk shape, with a diameter and occlusal height of $8 \mathrm{~mm}$, and presented a hole to access the screw. The crowns were cemented with zinc oxide cement (Temp Bond $\mathrm{NE}, \mathrm{KaVo}-\mathrm{Kerr}$ ), with $500 \mathrm{~g}$ of pressure, for $10 \mathrm{~min}$.

\section{Fatigue testing}

Mechanical fatigue was performed through a fatigue simulator
(ER-11000-Erios Plus, Equipment Technical and Scientific São Paulo, Brazil). Cycles were applied with an average force of 133 $\mathrm{N}$, at eccentric contact $(3 \mathrm{~mm})$, frequency of $4 \mathrm{~Hz}, 1$ x106 cycles. These cycles represent approximately 12 months of function and were replicated at a temperature of $37^{\circ} \mathrm{C} \pm 2{ }^{\circ} \mathrm{C}$.

After mechanical cycling, the abutment screw was subjected to reverse torque (data reported elsewhere [6]).

\section{Retorque and Fatigue testing}

Screws were torqued again with the same digital torque meter using $20 \mathrm{Ncm}(\mathrm{IH})$ and $30 \mathrm{Ncm}(\mathrm{EH})$.

Mechanical fatigue was repeated. At the end of fatigue, the screws were submitted to reverse torque to check the maintenance of the torque.

\section{Torque maintenance}

The remaining torque quantity in each tightened union was calculated, and these measurements were performed with the digital torque meter. The reverse torque values were converted into percentages related to the applied torque (retorque), through the following equation (1):

Reverse torque $(\%)=($ Reverse torque pos - loading / Applied torque) $\mathrm{x} 100$

\section{Qualitative analysis}

Screws from each group were selected for analysis through a scanning electron microscope (SEM JEOL, model JSM-5310, Munich, Germany), for the investigation of eventual alterations in the structure of the screw (threads). One specimen of each experimental group was sectioned with a precision cutter (IsoMet 1000, Buehler Ltd. IL, USA) on its longitudinal axis, allowing observation of the marginal adaptation of the prosthetic screw. The marginal adaptation was investigated by observing the gap between the screw and the implant using photomicrographs.

\section{Statistical Analysis}

The reverse torque averages $(\%)$ of each experimental group were submitted to statistical analysis using two-way ANOVA (factors: connections and screws coatings), using Minitab software (version 16.1 for Windows, Pennsylvania, USA) (5\% of significance level).

Data normality was accessed through the Kolmogorov-Smirnov Test (KS) for each experimental group. This confirms the possible utilization of parametric statistical analysis, as well as per data dispersion graphs.

\section{Results}

\section{Torque maintenance}

All groups presented Gaussian distribution according to the normality test. There was no significant interaction between the analyzed factors (screws coatings, $\mathrm{p}=0.638$; implant connections, $\mathrm{p}=0.615)$, nor amongst associated factors $(\mathrm{p}=0.765)$. And such 
findings were repeated between only fatigued groups (screws coatings, $\mathrm{p}=0.356$; implant connections, $\mathrm{p}=0.788$; associated factors, $\mathrm{p}=0.444)$. The Group IH-CONF presented the highest torque maintenance value, followed by EH-DD-DLCF and IHDLCF (Table 2).

Qualitative analysis: Surface qualitative analysis

In the qualitative analysis of screws, in the EH/IH-DLCF group (Fig. 1 and 2), there were lower screw thread damages when compared to the groups without nanofilm.

The EH/IH-CON and EH/IH-CONF groups presented numerous damages to screws threads (Fig. 1 and 2). The damages found on $\mathrm{EH} / \mathrm{IH} \mathrm{CON}$ presented larger dimensions, whereas the damages found in $\mathrm{EH} / \mathrm{IH}-\mathrm{CONF}$ presented higher quantity, but smaller dimensions.

In some areas, the DLC nanofilm was removed in the EH-DLCF group (Fig. 1) and IH-DLCF group (Fig. 2). The EH/IH-DDDLCF groups presented scattered granulation along the screws' surfaces and no alterations were observed (damage to threads) in the screw's structures (Fig. 1 and 2).

In the EH-DD-DLCF group (Fig. 1), the cervical portion of the screw presented regions of possible coating layer removal, although no titanium exposure occurred.

In the IH-DLCF group (Fig. 2), there was more incidence of nanofilm delamination (exposing the titanium) when compared to the EH-DLCF group (Fig. 1). In the IH-DD-DLCF group, screws presented areas in which the DD-DLC film was removed (Fig. 2). For both connections, the cervical portion of screws presented a smaller quantity of scattered granulation than the apical portion (Fig. 1 and 2).

\section{Qualitative analysis: Connection analysis}

The DLC and DD-DCL coatings did not interfere in the adaptation of the screw to the implant (Fig. 3-6). In the connections, more alterations were observed in $\mathrm{EH}$ groups when compared to IH groups, regardless of screw surface treatment (Fig. 3-6).

For cycled groups, the maladjustments were demonstrated more frequently in groups with external hexagonal connections (Fig. 3-6). The IH-DD-DLCF group (Fig. 6) presented the lowest gaps in maladjustment presence. Adding non-cycled groups to comparison, EH/IH-CON group (Fig. 3) presented the smaller gaps when compared to the fatigated groups.

Table 2. Experimental Groups, mean, standard deviation, coefficient of variance and maintenance torque values expressed in maximum and minimum percentage $(\%)$.

\begin{tabular}{|c|c|c|c|c|c|c|}
\hline Groups & Mean & $\begin{array}{c}\text { Standard } \\
\text { deviation }\end{array}$ & $\begin{array}{c}\text { Coefficient of } \\
\text { variance }\end{array}$ & $\begin{array}{c}\text { Minimum } \\
\mathbf{( \% )}\end{array}$ & \multicolumn{2}{|c|}{$\begin{array}{c}\text { Maximum } \\
\text { (\%) }\end{array}$} \\
\hline EH-CON & 43.1 & 26.9 & 62.44 & 9.7 & 80 & \\
\hline IH-CON & 50.9 & 29.9 & 58.74 & 15 & 85 & \\
\hline EH-CONF & 49.32 & 13.37 & 27.11 & 26.66 & 61.76 & \\
\hline IH-CONF & 59.91 & 7.82 & 13.05 & 52.17 & 70 & \\
\hline EH-DLCF & 48.66 & 17.42 & 35.79 & 33.33 & 76.66 & \\
\hline IH-DLCF & 44.63 & 18.85 & 42.25 & 19.04 & 60 & \\
\hline EH-DD-DLCF & 55.62 & 4.53 & 8.14 & 48.48 & 60 & \\
\hline IH-DD-DLCF & 53.19 & 15.14 & 28.46 & 35 & 76.19 & \\
\hline
\end{tabular}

Figure 1. Photomicrographs (SEM) of qualitative analysis, Extern Hexagonal connections groups. EH-CON group.

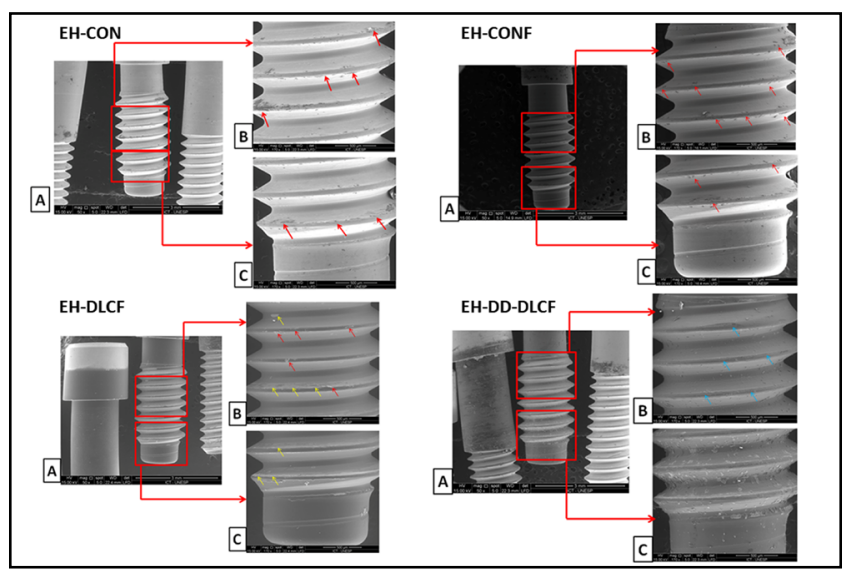

Legend A - Screw presenting damage in threads (original magnification 50x). B and C - Two areas in detail demonstrating countless damages (red arrows) on the threads of prosthetic screws (original magnification 170x). EH-CONF group. A - Screw presenting damage in all threads. B and C - Two areas in detail in which red arrows indicate injury in the threads. EH-DLCF group. A- Screw coated with DLC, presenting a few small damages to threads and areas of film detachment. B and C - Detail of small damages (red arrows) and coating removal areas (yellow arrows). EH-DD-DLCF group. A- Screw coated with DD-DLC presenting a surface with granules. B Detail of the screw. There were no damaged areas but there was an area presenting removal of a layer from the coating, without exposing titanium (blue arrows). C- The most apical part of the screw presenting granules distributed over the surface, without damage or removal of the film. 
Figure 2. Photomicrographs (SEM) of qualitative analysis, Intern Hexagonal connections groups. IH-CON group.

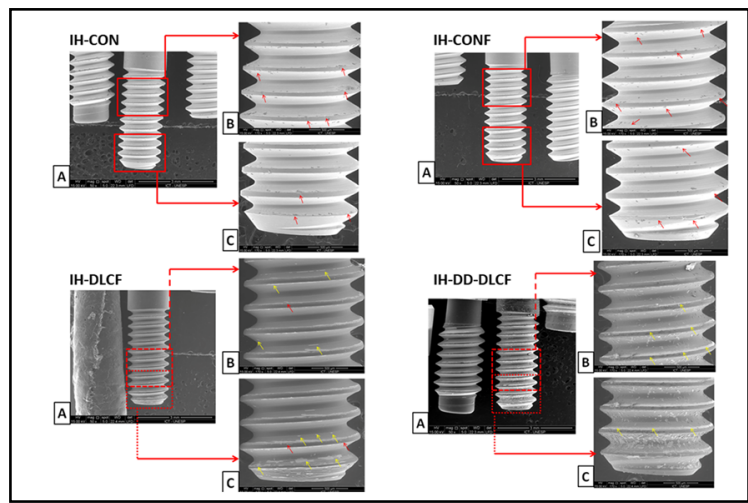

Legend A - Screw presenting damage in threads (original magnification 50x). B and C - Two areas in detail demonstrating screw up (red arrows) on the threads of prosthetic screws (original magnification 170x). IH-CONF group. A - Screw presenting damage. B and C - Two areas in detail in which red arrows indicate injury in the threads. IH-DLCF group. A - Screw coated with DLC, presenting darker color and damaged to threads. B and C - Damage is observed along threads (red arrows) and coating removal (yellow arrows) on some areas of the screw. IH-DD-DLCF group. A - DD-DLC coated screw with a granular surface. B - The screw did not present damage in the threads but demonstrated DD-DLC coating removal in some areas of the screw (yellow arrows).

Figure 3. Photomicrographs (SEM) of EH-CON group and EH-CONF group.

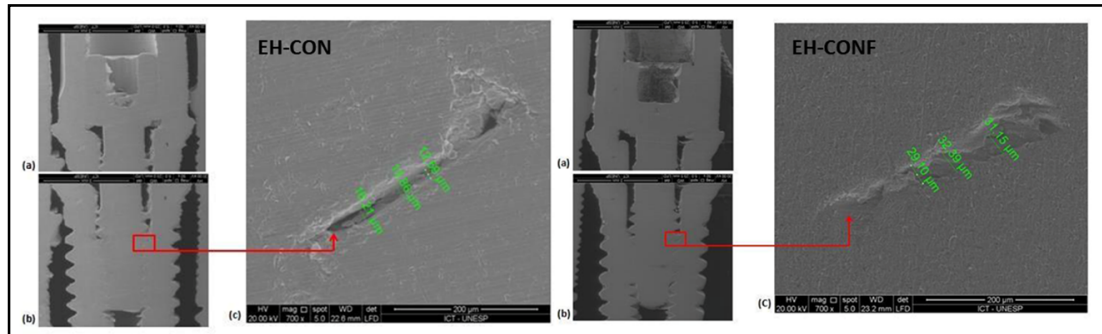

Legend (A) and (B) - The adaptation of the screw to the implant is observed (original magnification 50x) (C) - A gap was observed between the implant and the screw, which ranged from 12.50 to $16.21 \mu \mathrm{m}$, (original magnification 700x). EH-CONF group, (A) and (A) - The adaptation of the screw to the implant was observed (C) - A gap was observed between the implant and the screw, which ranged from 29.10 to $31.15 \mu \mathrm{m}$.

Figure 4. Photomicrographs (SEM) of EH-DLCF group and EH-DD-DLCF group.

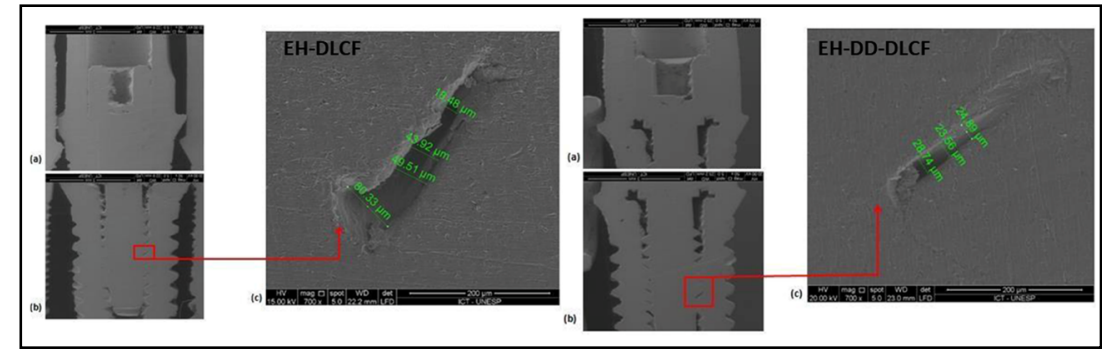

Legend (A) and (B) EH-DLCF group - The adaptation of the screw to the implant was observed (C) - There was a high maladjustment interval between the implant and the screw, which ranged from 18.48 to $80.33 \mu \mathrm{m}$. EH-DD-DLCF group, (A) and (B) - The adaptation of the screw to the implant was observed (C) - Maladjustment between the implant and the screw was observed, which ranged from 23.56 to $28.74 \mu \mathrm{m}$.

Figure 5. Photomicrographs (SEM) of IH-CON group and IH-CONF group.

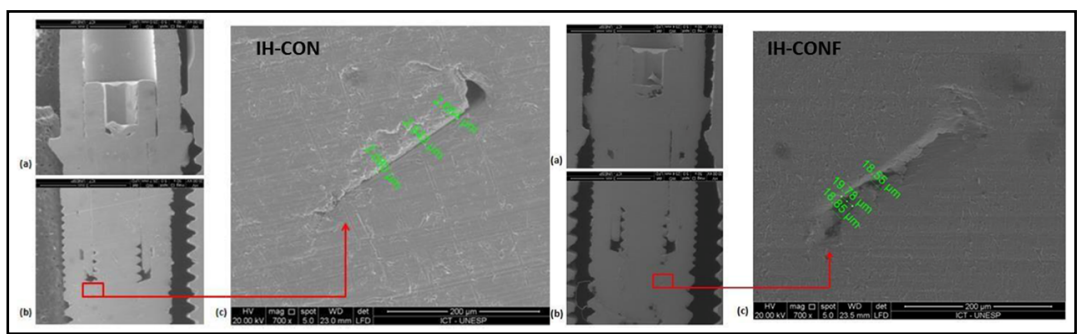

Legend (A) and (B) IH-CON group - The adaptation of the screw to the implant was observed (C) - Better adaptation was observed and the gap between the implant and the screw ranged from 2.08 and $2.94 \mu \mathrm{m}$. IH-CONF group, (A) and (B) - The adaptation of the screw to the implant was observed (C) - A gap was observed between the implant and the screw, which ranged from 18.55 to $19.78 \mu \mathrm{m}$.

\section{Discussion}

According to the results of this study, the null hypotheses were accepted; there were no significant differences among the groups. The mean value of torque maintenance before the retorque and mechanical recycling of our samples was described previously [6]; it was approximately $68 \%$. After complete the experiment, the mean torque maintenance value was approximately $50 \%$; this decrease in the removal torque values after retorque and the occlusal load occurred as expected, regardless of screw type[14] and these results are following literature [15-17]. The embedment, with gradual accommodation and adaptation between the contact interfaces, results in a reduction of the friction coefficient [17]. Besides that, the removal torque values tended to decrease pro- 


\section{Figure 6. Photomicrographs (SEM) of IH-DLCF group and IH-DD-DLCF group.}

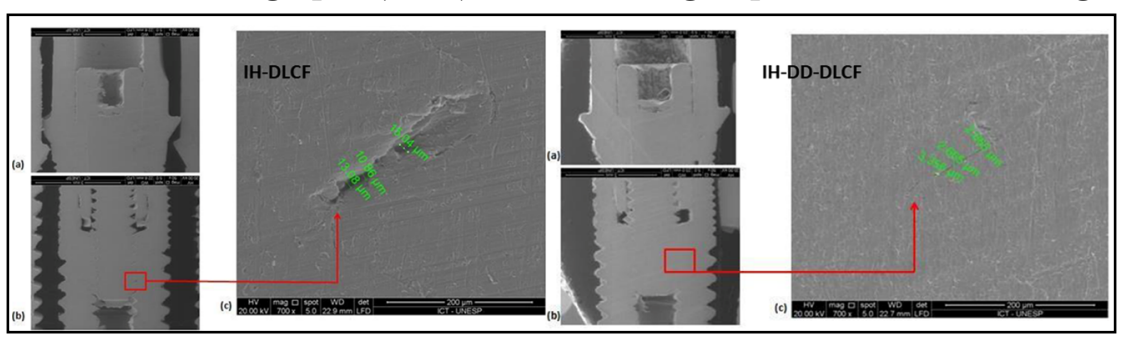

Legend (A) and (B) IH-CON group - The adaptation of the screw to the implant was observed (C) - Better adaptation was observed and the gap between the implant and the screw ranged from 2.08 and $2.94 \mu \mathrm{m}$. IH-CONF group, (A) and (B) - The adaptation of the screw to the implant was observed (C) - A gap was observed between the implant and the screw, which ranged from 18.55 to $19.78 \mu \mathrm{m}$.

portionally to the increase in the number of insertion/removal cycles [16].

It was expected an improvement of torque maintenance in the experimental coated groups. Dziedzic et al. reported that the carbon coating on the screw threads reduced the friction in the interface and improved the preload values [17] and consequently the clamping force exerted by the abutment on the implant platform. Due to the low friction coefficient of the DLC, the film should allow greater preload with the same torque, improving the stability of the joint [18]. Colpak \& Gumus coated abutment screws with DLC (Oerlikon Balzers) through the plasma vapor deposition method and reported higher reverse torque values in DLC coated abutment screws [19].

Additionally, diamond doped DLC films have unique properties when compared to pure nanocrystalline diamond films or metal-doped DLC films, which may provide advantages for electrochemical, optical-window, field emission, or tribological applications [11]. However, in this research, both coatings presented similar torque maintenance when compared to uncoated groups. Contradictory results may be explained by mechanical properties determined by the method of deposition. Herein we used PECVD. Each method has its advantages as well as disadvantages such as high levels of internal stress, poor adhesive properties, or high sensitivity to ambient conditions [20].

The literature demonstrates that external hexagonal connections generate higher stress along with the implant, promoting greater deformations than the internal hexagonal connection, thus $\mathrm{IH}$ has a more favorable biomechanical situation for the prosthetic performance [21], however, considering the limitations of the present study, none difference was demonstrated between $\mathrm{EH}$ and $\mathrm{IH}$ connections groups. Contradictorily, EH connections groups demonstrated significant differences while the torque maintenance values were more stable in the IH groups [6]; there were no significant differences among IH groups in Lepesqueur's study [6]. The authors reported high torque maintenance value in uncoated screws with external hexagonal connections when compared to groups coated with diamond-like carbon and coated with diamond-like carbon doped with diamond nanoparticles [6].

The fatigue simulation of retorqued screws resulted in the increase of screw surface irregularities, and consequently increased the coefficient of friction, but decreased the preload of the tightened joint [22]. There was no screw fracture or loosening of prosthesis in the presented study, so the stability of the tightened joint was kept after retorque, which is following literature [23].
Most uncoated screw damages confirm that the DLC film favors the wearing resistance and protect the coated surface and implant threads. Coating removal was higher in the DLC nanofilm group than the DD-DLC group, probably due to the greater roughness of DLC, even though DLC presented a higher critical load for delamination [6]. The elevated superficial roughness favors the coefficient of friction increase, which favors the DLC film removal during the torque of the screws and retorque procedures.

The granulation of DD-DLC coating over the screws is a characteristic of this type of coating. The granules were more frequent in the apical portion of the screw since the deposition process occurred with the specimen upside-down on a sample-holder; so this region was favored by the deposition process. The difference in the number of damages and titanium exposure caused by the coating removal of screws of different connections was attributed to the fact that the external hexagonal connection generates high stress along with the implant, promoting larger deformations than the internal hexagonal connections [21]. Besides that, the smaller micro-space found in the internal connection when compared to the external connection resulted in intimal relation between the implant and screw surfaces, favoring screwed joint clamping and promoting coating removal.

Our marginal adaptation findings corroborate with the literature [23]. The gaps between EH implant-pillar were larger than the ones observed between IH's, regardless of screw treatment. The groups with non-fatigued screws presented smaller gap values, consequently, their threads promoted better clamping between the screw and the implant.

A limitation of the study was the lack of rotational misfit measurement. Additional studies with the use of retorquing in accelerated life tests, the use of ceramic pillars, and retorqued screws fracture resistance evaluation should be carried out.

\section{Acknowledgements \& Declarations}

RCC thanks the scholarship from Coordination for the Improvement of Higher Education (CAPES - Coordenação de Aperfeiçoamento de Pessoal de Nível Superior - Brasil) - Finance Code 001, in São José dos Campos, Brazil. Authors thanks Conexão Sistemas de Prótese ${ }^{\circledR}$ (Campinas, SP, Brazil) that provided the implants to the research.

\section{Ethics approval and consent to participate}

Not applicable

Consent for publication

Not applicable 


\section{Availability of data and material}

Datasets are available from the corresponding author on reasonable request. The raw data and all related documents supporting the conclusions of this manuscript will be made available by the authors, without undue reservation, to any qualified researcher.

\section{Funding}

This work was partly supported by the Coordination for the Improvement of Higher Education (CAPES - Coordenação de Aperfeiçoamento de Pessoal de Nível Superior - Brasil) - Finance Code 001, in São José dos Campos, Brazil.

\section{Conclusion}

Based on these results, the surface of studied materials (coated/ uncoated) and the type of platform $(\mathrm{IH} / \mathrm{EH})$ do not interfere in the torque maintenance when a retorque is applied.

\section{References}

[1]. Srinivasan M, Meyer S, Mombelli A, Müller F. Dental implants in the elderly population: a systematic review and meta-analysis. Clin Oral Implants Res. 2017 Aug;28(8):920-930. Epub 2016 Jun 7. PubMed PMID: 27273468.

[2]. Araújo PM, Filho GS, Ferreira CF, Magalháes Benfatti CA, Cagna DR, Bianchini MA. Mechanical Complications Related to the Retention Screws of Prefabricated Metal Abutments With Different Angulations: A Retrospective Study With 916 Implants. Implant Dent. 2018 Apr;27(2):209-212. PubMed PMID: 29489548.

[3]. de Moraes SL, Verri FR, Santiago JF Jr, Almeida DA, de Mello CC, Pellizzer EP. A 3-D finite element study of the influence of crown-implant ratio on stress distribution. Braz Dent J. 2013 Nov-Dec;24(6):635-41. PubMed PMID: 24474362

[4]. Mombelli A, Hashim D, Cionca N. What is the impact of titanium particles and biocorrosion on implant survival and complications? A critical review. Clin Oral Implants Res. 2018 Oct;29 Suppl 18:37-53. PubMed PMID: 30306693.

[5]. Callan DP. Dental implant design and oral and systemic health. Compend Contin Educ Dent. 2007 Sep;28(9):482-4, 486-90, 492. PMID: 17907371.

[6]. Lepesqueur LS, de Figueiredo VM, Ferreira LL, Sobrinho AS, Massi M, Bottino MA, Nogueira Junior L. Coating dental implant abutment screws with diamondlike carbon doped with diamond nanoparticles: the effect on maintaining torque after mechanical cycling. Int J Oral Maxillofac Implants. 2015 Nov-Dec;30(6):1310-6. PubMed PMID: 26574857.

[7]. Kim SK, Lee JB, Koak JY, Heo SJ, Lee KR, Cho LR, Lee SS. An abutment screw loosening study of a Diamond Like Carbon-coated CP titanium implant. J Oral Rehabil. 2005 May;32(5):346-50. PubMed PMID: 15842243.

[8]. Wu L, Holloway BC, Beesabathina DP, Kalil C, Manos DM. Analysis of diamond-like carbon and Ti/MoS2 coatings on Ti-6Al-4V substrates for applicability to turbine engine applications. Surface and Coatings Technol- ogy. 2000 Aug 21;130(2-3):207-17.

[9]. Hauert R, Thorwarth K, Thorwarth G. An overview on diamond-like carbon coatings in medical applications. Surface and Coatings Technology. 2013 Oct 25;233:119-30.

[10]. Assunção WG, Delben JA, Tabata LF, Barão VA, Gomes EA, Garcia IR Jr. Preload evaluation of different screws in external hexagon joint. Implant Dent. 2012 Feb;21(1):46-50. PubMed PMID: 22228458.

[11]. Lian GD, Dickey EC, Ueno M, Sunkara MK. Ru-doped nanostructured carbon films. Diamond and Related Materials. 2002 Dec 1;11(12):1890-6.

[12]. Ivanov MG, Ivanov DM. Nanodiamond nanoparticles as additives to lubricants. InUltrananocrystalline Diamond: Synthesis, Properties and Applications: Second Edition 2012 (pp. 457-492).

[13]. Spazzin AO, Henrique GE, Nóbilo MA, Consani RL, Correr-Sobrinho L, Mesquita MF. Effect of retorque on loosening torque of prosthetic screws under two levels of fit of implant-supported dentures. Braz Dent J. 2010 Jan;21(1):12-7. PubMed PMID: 20464315.

[14]. Farina AP, Spazzin AO, Pantoja JM, Consani RL, Mesquita MF. An in vitro comparison of joint stability of implant-supported fixed prosthetic suprastructures retained with different prosthetic screws and levels of fit under masticatory simulation conditions. Int J Oral Maxillofac Implants. 2012 Jul-Aug;27(4):833-8. PubMed PMID: 22848885.

[15]. Farina AP, Spazzin AO, Consani RL, Mesquita MF. Screw joint stability after the application of retorque in implant-supported dentures under simulated masticatory conditions. J Prosthet Dent. 2014 Jun;111(6):499-504. Epub 2014 Jan 11. PubMed PMID: 24423456.

[16]. Cardoso M, Torres MF, Lourenço EJ, de Moraes Telles D, Rodrigues RC, Ribeiro RF. Torque removal evaluation of prosthetic screws after tightening and loosening cycles: an in vitro study. Clin Oral Implants Res. 2012 Apr;23(4):475-80. Epub 2011 Apr 4. PubMed PMID: 21457352.

[17]. Dziedzic DS, Nhata J, Jamcoski VH, Dziedzic M. Assessment of preload in carbon coated prosthetic screws. RSBO Revista Sul-Brasileira de Odontologia. 2012;9(2):137-42.

[18]. Colpak ED, Gumus HO. Effect of Surface Modifications of Abutment Screws on Reverse Torque Values: An In Vitro Study. Int J Prosthodont. 2020 Jul/Aug;33(4):401-409. PubMed PMID: 32639700.

[19]. Penkov OV, Pukha VE, Starikova SL, Khadem M, Starikov VV, Maleev MV, Kim DE. Highly wear-resistant and biocompatible carbon nanocomposite coatings for dental implants. Biomaterials. 2016 Sep;102:130-6. Epub 2016 Jun 15.PubMed PMID: 27336185.

[20]. Torcato LB, Pellizzer EP, Verri FR, Falcón-Antenucci RM, Santiago Júnior JF, de Faria Almeida DA. Influence of parafunctional loading and prosthetic connection on stress distribution: a 3D finite element analysis. J Prosthet Dent. 2015 Nov;114(5):644-51.Epub 2015 Jul 14. PubMed PMID: 26187105.

[21]. Bulaqi HA, Mousavi Mashhadi M, Safari H, Samandari MM, Geramipanah F. Dynamic nature of abutment screw retightening: finite element study of the effect of retightening on the settling effect. J Prosthet Dent. 2015 May;113(5):412-9. Epub 2015 Mar 4. PubMed PMID: 25749092.

[22]. Montero J, Manzano G, Beltrán D, Lynch CD, Suárez-García MJ, CastilloOyagüe R. Clinical evaluation of the incidence of prosthetic complications in implant crowns constructed with UCLA castable abutments. A cohort follow-up study. J Dent. 2012 Dec;40(12):1081-9. Epub 2012 Sep 12. PubMed PMID: 22982530.

[23]. Diez JS, Brigagão VC, Cunha L, Neves AC, da Silva-Concilio LR. Influence of diamondlike carbon-coated screws on the implant-abutment interface. Int J Oral Maxillofac Implants. 2012 Sep-Oct;27(5):1055-60. PubMed PMID: 23057017. 